\title{
Improvement of organ damage by a non-depressor dose of imidapril in diabetic spontaneously hypertensive rats
}

\author{
NARUYA TOMITA ${ }^{1}$, KEITA YAMASAKI $^{1}$, KEIKO IZAWA ${ }^{1}$, YASUO KUNUGIZA ${ }^{1}$, \\ MARIANA K. OSAKO ${ }^{1}$, TOSHIO OGIHARA ${ }^{2}$ and RYUICHI MORISHITA ${ }^{1}$ \\ ${ }^{1}$ Division of Clinical Gene Therapy, ${ }^{2}$ Department of Geriatric Medicine, \\ Osaka University Graduate School of Medicine, Suita 565-0871, Japan
}

Received July 28, 2006; Accepted September 29, 2006

\begin{abstract}
Many clinical trials have demonstrated that angiotensin converting enzyme inhibitors have protective effects on organ damage, suggesting the importance of inhibition of the renin-angiotensin system. In this study, we investigated the effects of a non-depressor dose of imidapril on organ damage induced by diabetes and hypertension. Diabetes was induced by an intravenous injection of streptozotocin (STZ, $40 \mathrm{mg} / \mathrm{kg}$ ) in 15 -week-old male spontaneously hypertensive rats (SHR). Imidapril (2 mg/ $\mathrm{kg}$ /day) or vehicle was given orally for 28 days, and then the heart weight, left ventricle mass (LVM), urinary albumin excretion (UAE) and endothelial function were examined, as well as the urinary NOx level and local hepatocyte growth factor (HGF) expression. There were no significant differences between the treated groups in systolic blood pressure and plasma parameters. On the other hand, UAE was significantly suppressed in the imidapril-treated group $(450 \pm 44 \mathrm{mg} /$ day) compared to the vehicle-treated group $(963 \pm 182 \mathrm{mg} /$ day $)(\mathrm{p}<0.01)$. Moreover, endothelial function assessed by dilative reaction to acetylcholine as well as cardiac hypertrophy assessed by both heart/body weight ratio and LVM were significantly improved in the imidapriltreated group $(\mathrm{p}<0.05$ and $\mathrm{p}<0.01$, respectively). The urinary NOx concentration and local HGF expression in vessel walls were also significantly increased in the imidapril-treated group $(\mathrm{p}<0.01)$. A non-depressor dose of imidapril showed protective effects against organ damage in diabetic SHR, which may be partially due to the increase of HGF and NO.
\end{abstract}

Correspondence to: Dr Naruya Tomita, Division of Nephrology, Department of Internal Medicine, Kawasaki Medical School, 577 Matsushima, Kurashiki 701-0192, Japan

E-mail: tomita@med.kawasaki-m.ac.jp

Key words: endothelial function, diabetes, hypertension, angiotensin converting enzyme inhibitor, hepatocyte growth factor, nitric oxide

\section{Introduction}

Diabetes and hypertension are major risk factors for cardiovascular diseases. About three quarters of adults with diabetes die of cardiovascular diseases. It is well known that the prevalence of hypertension in the diabetic population is increased, and the concomitant diabetes further increases the risk of cardiovascular mortality (1). Both diabetes and hypertension are associated with cardiac and vascular hypertrophy, which are considered to be important pathological processes leading to the subsequent development of cardiovascular diseases $(2,3)$. One of the most important therapeutic approaches to prevent diabetic and hypertensive organ damage is strict blood glucose control, but blood pressure must be rigorously controlled as well. (4). Inhibition of the renin-angiotensin system (RAS) with angiotensin converting enzyme (ACE) inhibitors has been shown in landmark clinical trials to dramatically attenuate the inexorable decline in organ damage associated with both the diabetic and nondiabetic status (5-9). Because of their protective effects on organ damage induced by diabetes and/or hypertension, ACE inhibitors are regarded as a first-line antihypertensive therapy for patients suffering from these diseases (10-12). Similarly, the beneficial effects of ACE inhibitors on organ damage have been reported in many animal experiments (13-16). ACE inhibitors are one of the most frequently used antihypertensive drugs throughout the world. In fact, in most landmark clinical trials, the blood pressure of ACE inhibitortreated groups was decreased. By comparing groups treated with other classes of antihypertensive drugs without RAS inhibition, their beneficial effects were suggested not to be due solely to the lowering of blood pressure. From these data, additional beneficial effects on organ damage have been recognized beyond the blood pressure-lowering effects. However, we cannot tell if this is actually the case, as long as blood pressure is decreased. In this study, we showed that an ACE inhibitor, imidapril, has beneficial effects on organ damage at a non-depressor dose in diabetic hypertensive rats. Moreover, recently, the direct induction of nitric oxide (NO) by hepatocyte growth factor (HGF) has been reported (17). The mechanisms of the beneficial effects on organ damage were also examined in terms of HGF and NO production. 


\section{Materials and methods}

Experimental design. Diabetes was induced in male spontaneously hypertensive rats (SHR) (15 weeks old; Charles River Breeding Laboratories, Osaka, Japan) by a single injection of streptozotocin (STZ) $(40 \mathrm{mg} / \mathrm{kg}$ in $50 \mathrm{mM}$ citric acid buffer, $\mathrm{pH} 4.5$ ). Then, 7 days later, a blood sample was obtained periorbitally after $8 \mathrm{~h}$ of fasting. Only rats having a blood glucose concentration $>300 \mathrm{mg} / \mathrm{dl}$ were kept in the protocol and randomized for the experiments. The rats were maintained and bred under conventional conditions with food and tap water provided ad libitum, except on the days of blood sampling, and a 12-h light/12-h dark photoperiod. These rats were divided into two groups and treated for 28 days with vehicle (distilled water) or imidapril $(2 \mathrm{mg} / \mathrm{kg} /$ day $)$ (each group, $n=10)$. Drugs were donated from Tanabe Pharmaceutical Company (Osaka, Japan). Animals were randomly allocated to each group, and drugs were administered by gavage. After treatment, the rats were sacrificed by decapitation and a blood sample was collected. Male WistarKyoto rats (WKY) and SHR (15 weeks old; Charles River Breeding Laboratories) were used as controls. Systolic blood pressure (SBP), heart rate (HR) and body weight (BW) were measured in a conscious state using the tail-cuff method with a sphygmomanometer (Softron Co. Ltd., Tokyo, Japan) every 7 days. All rats were free to drink water and eat standard laboratory rat chow (containing $11.3 \mathrm{mEq} \mathrm{Na}+100 \mathrm{~g}, 32.6 \mathrm{mEq}$ $\mathrm{K}^{+} / 100 \mathrm{~g}, 24.6 \%$ protein by weight; Oriental Yeast Co., Osaka, Japan). Throughout the experiment, the rats were housed in metabolic cages under light- and temperature-controlled conditions.

Evaluation of vasodilator properties in response to acetylcholine. Freshly harvested aortas were cleaned of fat and connective tissues, cut into helical strips, and mounted in 30-ml organ baths containing Krebs-Henseleit buffer (KHB; $120 \mathrm{mM} \mathrm{NaCl}, 4.7 \mathrm{mM} \mathrm{KCl}, 2.5 \mathrm{mM} \mathrm{CaCl}_{2}, 1.2 \mathrm{mM} \mathrm{MgSO}_{4}$, $1.2 \mathrm{mM} \mathrm{KH}_{2} \mathrm{PO}_{4}, 25 \mathrm{mM} \mathrm{NaHCO}$, and $5.5 \mathrm{mM}$ glucose, $\mathrm{pH} 7.4)$ maintained at $37^{\circ} \mathrm{C}$ and oxygenated with $95 \% \mathrm{O}_{2} /$ $5 \% \mathrm{CO}_{2}$ (16). Vessels were equilibrated for $60 \mathrm{~min}$, with changes of the bathing fluid every $15 \mathrm{~min}$. Isometric tension studies were performed using a Grass model 7D polygraph. The optimal resting tension was determined in baseline studies, and the response to vasoactive drugs was then determined as described previously $(16,18)$. Cumulative doseresponse curves to phenylephrine $\left(\mathrm{PE} ; 10^{-9}-10^{-4} \mathrm{M}\right)$ were established. The vessels were then submaximally precontracted with PE (typically $3 \times 10^{-6} \mathrm{M}$ ), and the endothelial function was evaluated by means of vascular relaxation to acetylcholine $\left(10^{-9}-10^{-4} \mathrm{M}\right)$. Nitric oxide mediation of acetylcholine responses was confirmed by blocking acetylcholine-induced relaxation by $\mathrm{N} \omega$-nitro-Larginine methyl ester (L-NAME) (1 mM), a specific competitive inhibitor of nitric oxide synthase. Contractile responses were measured from the polygraph chart and expressed as a percentage of the maximal contraction, or for relaxation, as a percentage of the precontracted tension.

Immunohistochemical analyses. Aortas were stained for immunoreactive HGF protein as described previously
$(16,18)$. Tissue specimens $(6-\mu \mathrm{M}$ thick) from the midsection of the aorta were sectioned at $60-\mu \mathrm{m}$ intervals along the vessel in a proximal to distal fashion. Sections were stained with an enzyme immunohistochemical kit (Histostain-SP kit, Zymed Lab. Inc., San Francisco, CA) with rabbit polyclonal antibody against rat HGF (1:1000 dilution; Tokushu Meneki Institute, Tokyo, Japan) that was tested for cross-reactivity with rat HGF (19-21). Cell counting analysis was performed using a computerized morphometry system, NEXUS 6400 (Kashiwagi Research Co., Tokyo, Japan) by individuals unaware of the treatment each animal had received, as previously described (22). Intra-observer variability was determined from triplicate measurements performed by one observer for all sections. The mean \pm SD differences among measurements made by the same observer were $2.2 \pm 0.4 \%$. Inter-observer variability was determined from measurements of 10 randomly selected sections performed by a second observer in addition to the first observer. The difference between measurements made by the two observers was $3.3 \pm 0.4 \%$. These observers were blinded to other data concerning the rats, as well as to the results of the other observers. If the internal elastic lamina or media showed any evidence of crenulation or compression, the section was not used.

Histological analysis. Animals were sacrificed under injection of sodium pentobarbital (50 mg/kg i.p.) on day 28 . The aortas and kidneys were fixed in $4 \%$ paraformaldehyde after perfusion with phosphate-buffered saline (PBS). Then, $5-\mu \mathrm{m}$-thick paraffin sections of aorta were stained with hematoxylin and eosin (H\&E), and the kidneys were stained with periodic acid-methenamine silver (PAS).

Measurement of plasma parameters. To examine the effects of treatment with imidapril and vehicle on lipid metabolism and kidney function, serum triglyceride (TG), total cholesterol (T-chol), high density lipoprotein cholesterol (HDL-chol), blood glucose, blood urea nitrogen (BUN) and creatinine (Cre) were measured after the rats were killed. These levels were determined using a commercially available assay kit (Sigma Chemical Co., St. Louis, MO) with a modification of the assay protocol suggested by the supplier.

Measurement of urinary albumin excretion, creatinine and NOx. A twenty-four-hour urine collection from the rats that were individually housed in metabolic cages was performed. The rats were fasted during the collection period, but were allowed free access to water. Urine albumin excretion was measured by a sulfosalicylic acid method as previously described (23). Creatinine was enzymatically determined with Creatinine F L-Type R1 and R2 (Wako Chemicals, Osaka, Japan). Total NOx was determined using the Nitrate/Nitrite Colorimetric assay kit of Cayman Chemical (ITK Diagnostics, Uithoorn, Netherlands).

Cardiac echography. In vivo heart dimensions and function were evaluated by standard echocardiography using an echocardiographic system (Power Vision 6000, Toshiba Medical Systems Corporation, Tokyo, Japan) equipped with a 7.5-MHz mechanical probe (focus depth set at $3.0 \mathrm{~cm}$, sectorial angle of $60^{\circ}$ ). The rats were examined, with the 
Table I. Changes in body weight, heart rate and systolic blood pressure.

\begin{tabular}{lcccccc}
\hline & & Day 0 & Day 7 & Day 14 & Day 21 & Day 28 \\
\hline Body weight (g) & WKY & $343 \pm 4$ & $353 \pm 4$ & $363 \pm 4$ & $374 \pm 5$ & $378 \pm 6$ \\
& SHR & $321 \pm 8$ & $333 \pm 8$ & $341 \pm 8$ & $356 \pm 8$ & $362 \pm 8$ \\
& Vehicle & $269 \pm 4$ & $252 \pm 4$ & $242 \pm 5$ & $233 \pm 5$ & $220 \pm 4$ \\
& Imidapril & $251 \pm 7$ & $236 \pm 7$ & $222 \pm 9$ & $210 \pm 10$ & $204 \pm 9$ \\
Heart rate (beats/min) & WKY & $384 \pm 13$ & $412 \pm 15$ & $428 \pm 6$ & $435 \pm 4$ & $424 \pm 6$ \\
& SHR & $396 \pm 14$ & $404 \pm 12$ & $419 \pm 18$ & $465 \pm 18$ & $446 \pm 9$ \\
& Vehicle & $357 \pm 14$ & $310 \pm 17$ & $357 \pm 14$ & $255 \pm 7$ & $278 \pm 12$ \\
Systolic blood pressure & Imidapril & $355 \pm 9$ & $285 \pm 9$ & $355 \pm 11$ & $245 \pm 7$ & $269 \pm 8$ \\
(mmHg) & WKY & $126 \pm 1$ & $127 \pm 4$ & $127 \pm 4$ & $127 \pm 2$ & $127 \pm 1$ \\
& SHR & $189 \pm 9$ & $186 \pm 7$ & $184 \pm 8$ & $185 \pm 7$ & $188 \pm 5$ \\
& Vehicle & $178 \pm 5$ & $183 \pm 6$ & $185 \pm 3$ & $172 \pm 2$ & $162 \pm 6$ \\
& Imidapril & $177 \pm 3$ & $182 \pm 3$ & $183 \pm 2$ & $175 \pm 5$ & $161 \pm 4$ \\
\hline
\end{tabular}

Measurements were performed on day 0 (before starting treatment), 7, 14, 21 and 28. WKY, untreated WKY; SHR, untreated SHR; Vehicle, diabetic SHR treated with vehicle; Imidapril, diabetic SHR treated with imidapril; n=8/group. Values are mean \pm SEM.

Table II. Plasma parameters on day 28.

\begin{tabular}{lcccccc}
\hline & $\begin{array}{c}\text { TG } \\
(\mathrm{mg} / \mathrm{dl})\end{array}$ & $\begin{array}{c}\text { T-Cho } \\
(\mathrm{mg} / \mathrm{dl})\end{array}$ & $\begin{array}{c}\text { HDL-Cho } \\
(\mathrm{mg} / \mathrm{dl})\end{array}$ & $\begin{array}{c}\text { Glucose } \\
(\mathrm{mg} / \mathrm{dl})\end{array}$ & $\begin{array}{c}\text { BUN } \\
(\mathrm{mg} / \mathrm{dl})\end{array}$ & $\begin{array}{c}\text { Cre } \\
(\mathrm{mg} / \mathrm{dl})\end{array}$ \\
\hline WKY & $82 \pm 9$ & $112 \pm 2$ & $56 \pm 2$ & $164 \pm 7$ & $17 \pm 1$ & $0.18 \pm 0.01$ \\
SHR & $89 \pm 8$ & $118 \pm 8$ & $49 \pm 5$ & $158 \pm 8$ & $21 \pm 3$ & $0.29 \pm 0.01^{*}$ \\
Vehicle & $353 \pm 75^{*}$ & $88 \pm 8$ & $39 \pm 4$ & $795 \pm 42^{*}$ & $36 \pm 3^{*}$ & $0.26 \pm 0.01^{*}$ \\
Imidapril & $391 \pm 39^{*}$ & $96 \pm 8$ & $43 \pm 4$ & $757 \pm 52^{*}$ & $38 \pm 2^{*}$ & $0.24 \pm 0.01^{*}$ \\
\hline
\end{tabular}

Measurements were performed on day 28. Blood samples were collected just after sacrificing. WKY, untreated WKY; SHR, untreated SHR; Vehicle, diabetic SHR treated with vehicle; Imidapril, diabetic SHR treated with imidapril; $n=8 /$ group; ${ }^{*} \mathrm{p}<0.01$ vs WKY. Values are mean \pm SEM.

chests closed, under diethyl ether anesthesia, in the left lateral decubitous position. To identify the phase of the cardiac cycle, three electrodes were attached to their paws to obtain a simultaneous electrocardiographic tracing. At each interval, echocardiographic parameters obtained in the control group were assumed as normal values. Left ventricular dimensions were obtained by M-mode echocardiography. Left ventricle mass (LVM) was calculated as described previously (24).

Measurements of tissue HGF concentration. The aortas were promptly removed without excess fat after perfusion from the apex of the heart with saline, frozen in liquid nitrogen, and stored at $-70^{\circ} \mathrm{C}$ until use. On the day of extraction, the tissue was thawed at $4^{\circ} \mathrm{C}$, and homogenized with a polytron in assay solution. Each specimen was centrifuged at $20,000 \mathrm{x} \mathrm{g}$ for $30 \mathrm{~min}$ at $4^{\circ} \mathrm{C}$ to remove the lysates. Then, the HGF concentration was determined by EIA (HGF EIA kit, Tokushu Meneki Institute) (22).

Statistical analysis. All values are expressed as mean \pm SEM. Analysis of variance with subsequent Bonferroni/Dunnet's tests was employed to determine the significance of differences in multiple comparisons. Values of $\mathrm{p}<0.05$ were considered statistically significant.

\section{Results}

There were no significant changes in body weight, systolic blood pressure (SBP) and heart rate (HR) in rats treated with imidapril and vehicle as shown in Table I. Concerning SBP, we performed a preliminary study to determine the dose of imidapril that did not affect blood pressure. From this point of view, the results of SBP were exactly as we had expected. Moreover, there were no significant differences in plasma parameters such as TG, T-chol, HDL-chol, BUN, Cre and blood glucose level in the groups treated with imidapril and vehicle as shown in Table II. As shown in Table I, the induction of diabetes obstructed the increase of body weight in accordance with age, which is consistent with previous reports $(1,12)$.

Next, we examined the protective effect of imidapril on damage of the heart. It is well known that cardiac hypertrophy 
$\mathrm{A}$

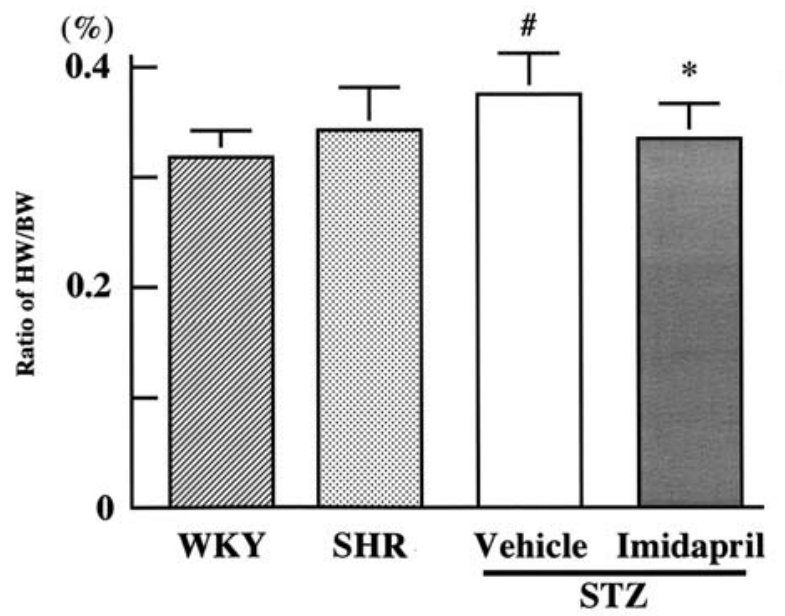

$\mathrm{B}$

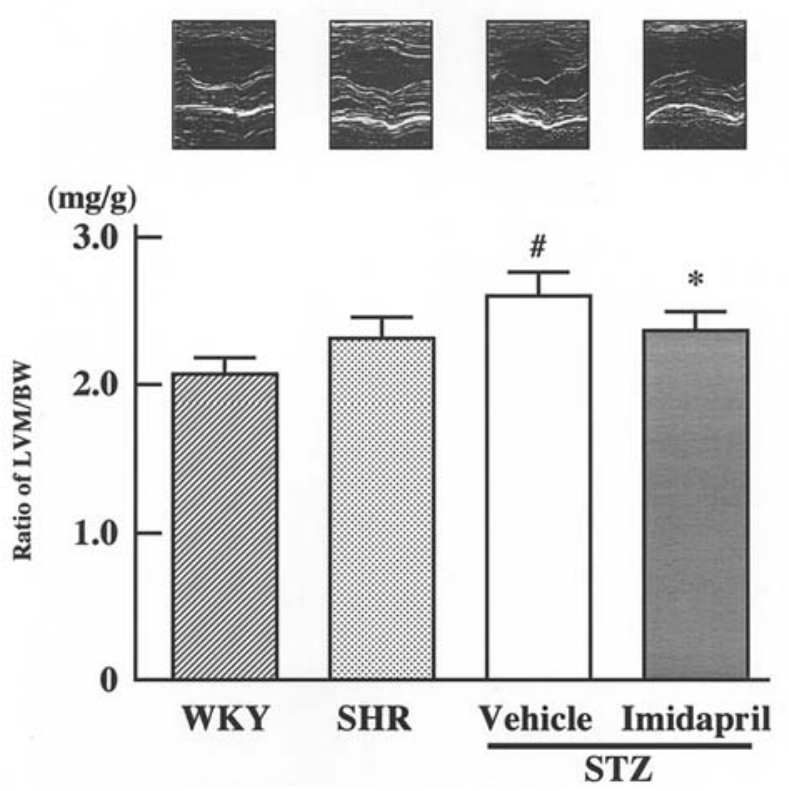

Figure 1. (A) Ratio of heart weight to body weight (g/g). (B) Representative photographs of echocardiography and quantitative data of echocardiography for left ventricle weight. Echocardiography was performed on day 28 just before sacrificing. WKY, untreated WKY; SHR, untreated SHR; Vehicle, diabetic SHR treated with vehicle; Imidapril, diabetic SHR treated with imidapril; HW, heart weight; LVM, left ventricle weight; BW, body weight. STZ indicates the induction of diabetes by injection of streptozotocin. ${ }^{*} \mathrm{p}<0.05$ vs vehicle; ${ }^{*} \mathrm{p}<0.01$ vs WKY; $\mathrm{n}=7 /$ group. Values are mean \pm SEM.

is induced by hypertension (24). Moreover, the existence of diabetes in addition to hypertension further promotes cardiac hypertrophy (25). Our data presented in this study are consistent with previous reports, as shown in Fig. 1. As shown in Fig. 1A, imidapril significantly decreased the ratio of heart weight to body weight (imidapril, $0.325 \pm 0.01$; vehicle, $0.354 \pm 0.01 ; \mathrm{p}<0.01$ vs vehicle). This result was also partially supported by ultrasound analysis performed on day 28 just before sacrifice, as shown in Fig. 1B. The ratio of LVM/BW was reduced by treatment with imidapril compared to the control group treated with vehicle (imidapril, $2.42 \pm 0.28 \mathrm{mg} / \mathrm{g}$; vehicle, $2.76 \pm 0.31 \mathrm{mg} / \mathrm{g} ; \mathrm{p}<0.05 \mathrm{vs}$ vehicle).

Urinary albumin excretion (UAE) is believed to be one of the predictors of cardiovascular events. Hypertension and/or
A

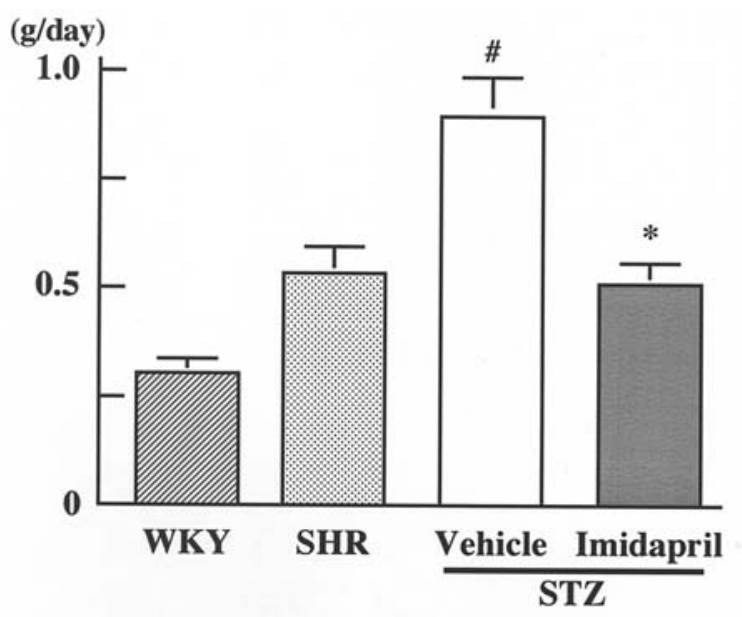

B
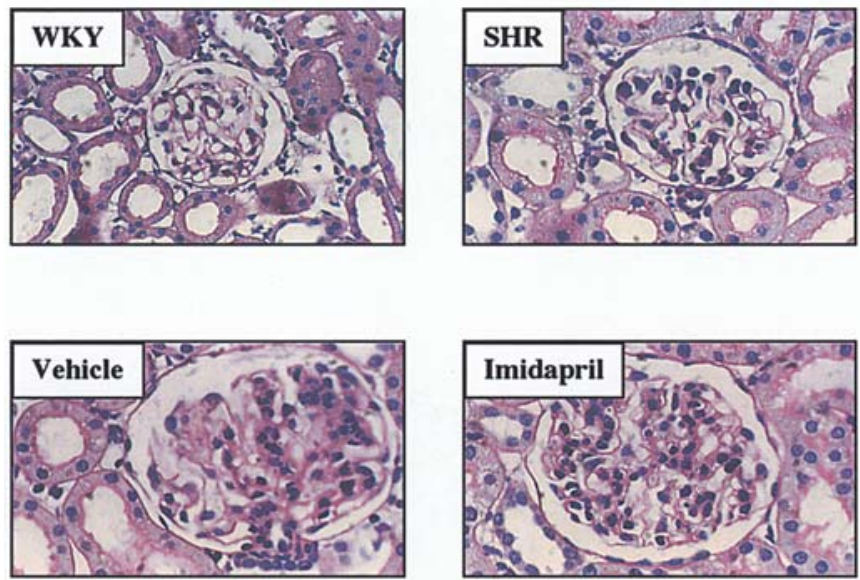

Figure 2. (A) Urinary albumin excretion in rats on day 28. WKY, untreated WKY; SHR, untreated SHR; Vehicle, diabetic SHR treated with vehicle; Imidapril, diabetic SHR treated with imidapril. STZ indicates the induction of diabetes by injection of streptozotocin. ${ }^{*} \mathrm{p}<0.01$ vs vehicle; ${ }^{*} \mathrm{p}<0.01$ vs WKY; $n=7$ /group. Values are mean \pm SEM. (B) Representative photographs of kidney stained with PAS on day 28. WKY, kidney in untreated WKY; SHR, kidney in untreated SHR; Vehicle, kidney in diabetic SHR treated with vehicle; Imidapril, kidney in diabetic SHR treated with imidapril. All kidneys were from the left side. There were no significant differences between right and left kidneys in each group. Magnification x100.

diabetes have been reported to increase UAE. As shown in Fig. 2A UAE was greater in SHR than in WKY, and UAE in diabetic SHR was greater than that in SHR. Expectedly, UAE measured on day 28 was significantly reduced in the imidapril-treated group compared to the control group treated with vehicle, as shown in Fig. 2A (imidapril, $450 \pm 44 \mathrm{mg} /$ day; vehicle, $963 \pm 182 \mathrm{mg} / \mathrm{dl}, \mathrm{p}<0.01$ vs vehicle). However, there was no improvement in renal histology assessed by PASstained sections. Enlargement of glomeruli was observed in the kidneys of SHR and diabetic SHR (vehicle) compared to WKY control as shown in Fig. 2B. Treatment with a nondepressor dose of imidapril for 28 days did not affect the histological changes induced by diabetes and hypertension in PAS-stained sections (Fig. 2B).

It is also known that hypertension and diabetes induce the impairment of endothelial function, which is often evaluated by the dilator response to acetylcholine in animal models. As previously reported, the dilator response of the aorta in SHR 
A

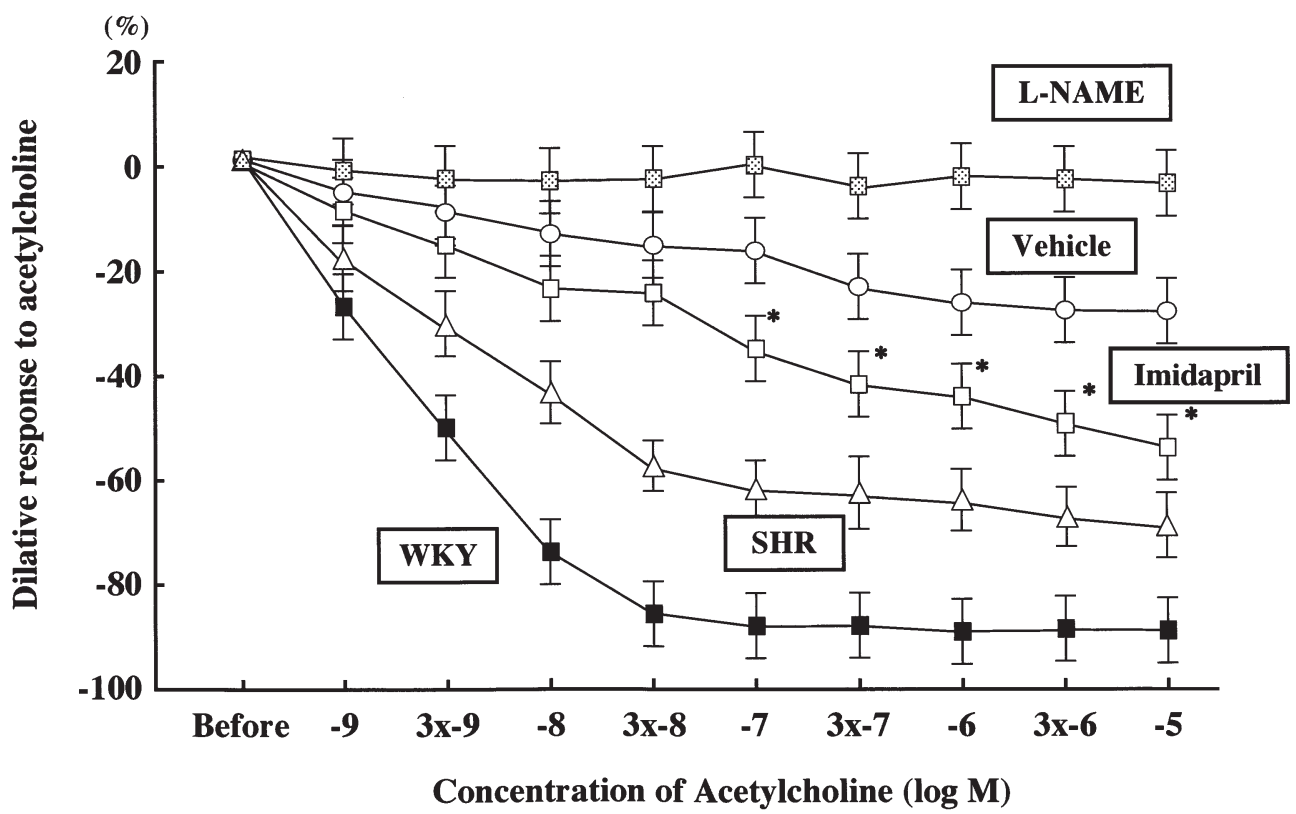

B
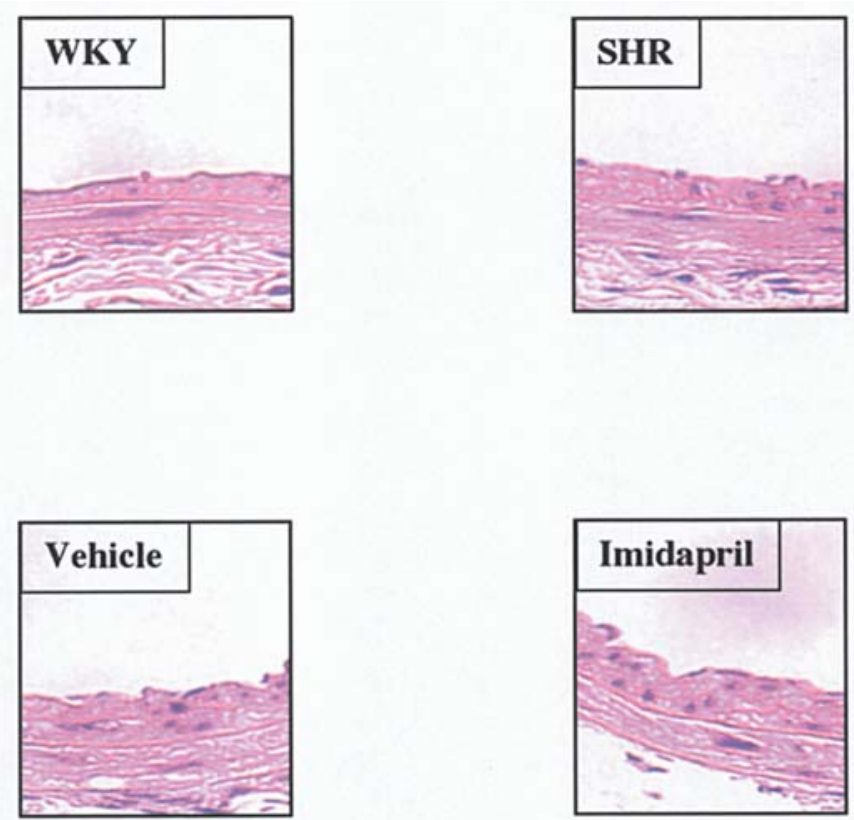

Figure 3. (A) Vasodilator response to acetylcholine of aorta on day 28. WKY, aorta from untreated WKY; SHR, aorta from untreated SHR; Vehicle, aorta from diabetic SHR treated with vehicle; Imidapril, aorta from diabetic SHR treated with imidapril; L-NAME, aorta from WKY pretreated with L-NAME. ${ }^{*} \mathrm{p}<0.05$ vs vehicle; $n=5 /$ group. (B) Representative photographs of aorta stained with H\&E on day 28. Magnification x100.

was impaired as compared to control WKY, and further impairment was observed in diabetic SHR $(16,18)$. In contrast, dilator response to acetylcholine of the aorta from diabetic SHR treated with imidapril showed significant improvement as compared to the aorta of the control group treated with vehicle $(\mathrm{p}<0.01)($ Fig. $3 \mathrm{~A})$. Moreover, there were no significant differences in the vasodilator response between diabetic SHR treated with vehicle and diabetic SHR (data not shown). The endothelium-dependent dilation of the aorta from diabetic SHR treated with imidapril was also supported by the observation that the increase in dilation was completely abolished by the administration of L-NAME
(Fig. 3A). Similarly, the endothelium-dependent dilation of the aorta from diabetic SHR treated with vehicle was also completely abolished by the administration of L-NAME (data not shown). Furthermore, we examined the histological changes in H\&E-stained sections of the aorta of diabetic SHR treated with imidapril or vehicle by assessing the ratio of neointima to media (N/M ratio), finding that there were no structural changes in these samples, as shown in Fig. 3B.

To examine the mechanism of the improvement of endothelial function, we first measured the urinary NOx excretion level, which is related to the production of NO in plasma, which in turn improves endothelial function. Urinary 


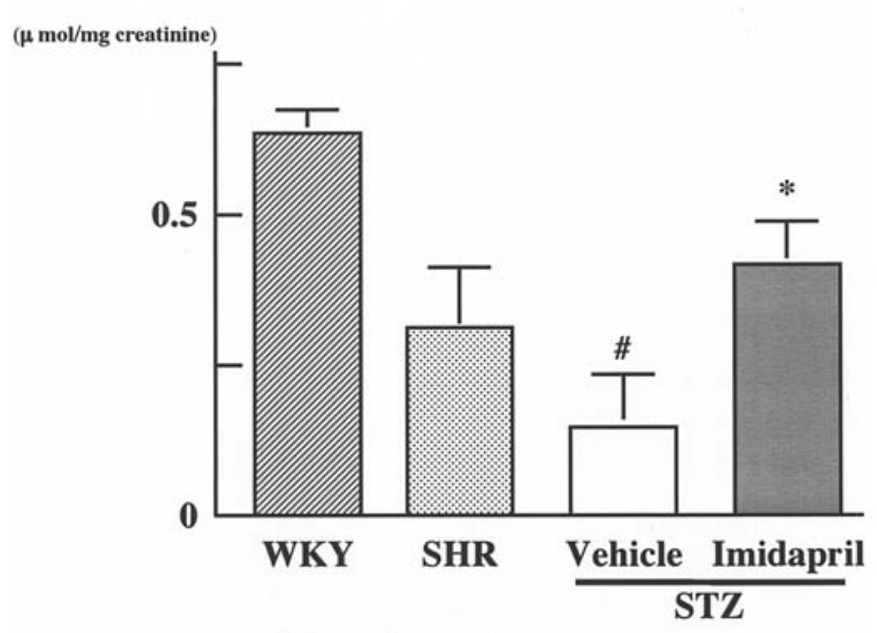

Figure 4. Urinary NOx excretion on day 28 measured by EIA. WKY, untreated WKY; SHR, untreated SHR; Vehicle, diabetic SHR treated with vehicle; Imidapril, diabetic SHR treated with imidapril. STZ indicates the induction of diabetes by injection of streptozotocin. ${ }^{*} \mathrm{p}<0.01$ vs vehicle; ${ }^{\#} \mathrm{p}<0.01$ vs WKY; $\mathrm{n}=7$ /group. Values are mean \pm SEM

NOx excretion was significantly decreased in SHR compared to WKY control (Fig. 4). Moreover, that in diabetic SHR was further decreased compared to that in SHR (data not shown). Expectedly, the urinary NOx excretion in diabetic SHR treated with imidapril was significantly increased, however, treatment with vehicle failed to induce the recovery of urinary NOx excretion, as shown in Fig. 4 (imidapril, $0.39 \pm 0.03 \mu \mathrm{mol} / \mathrm{mg}$ creatinine; vehicle, $0.13 \pm 0.02 \mu \mathrm{mol} / \mathrm{mg}$ creatinine; $\mathrm{p}<0.01$ vs vehicle).

We believed that an increase in NO production might partially explain the improvement of organ damage, especially endothelial dysfunction, induced by diabetes and hypertension. Finally, we examined the contribution of HGF in the improvement of organ damage in this study, because our previous reports documented that local HGF production in the blood vessels was markedly decreased in a diabetes model (26-28). Moreover, the recovery of HGF induced by gene transfer improved the endothelial dysfunction in a balloon-injury model (29). We, then, examined the contribution of HGF in the improvement of organ damage in diabetic SHR in vivo by using immunohistochemical staining and direct measuring of HGF content in the vessel walls. In control WKY, positive immunohistochemical staining for HGF protein was detected in VSMC in the media and endothelial cells $(22.1 \pm 2.7 \%)$. In contrast, a significant reduction of vascular HGF protein was observed in SHR and diabetic SHR treated with vehicle compared to control WKY (SHR, 13.2 $\pm 1.9 \%$; vehicle, $9.9 \pm 1.1 \%$; p $<0.01$ vs WKY) (Fig. $5 \mathrm{~A})$. To note, vascular HGF protein was significantly increased in diabetic SHR treated with imidapril as compared to vehicle (imidapril, 19.4 $\pm 2.9 \%$; vehicle, $9.9 \pm 1.1 \%$; $<<0.01$ vs vehicle) (Fig. 5A). The increase in vascular HGF protein was mainly localized in the media (data not shown). We also measured concentrations of vascular HGF, which showed almost the same results observed in the immunohistochemical study. The HGF concentration in the vessel wall was decreased in SHR compared to WKY, and further
A

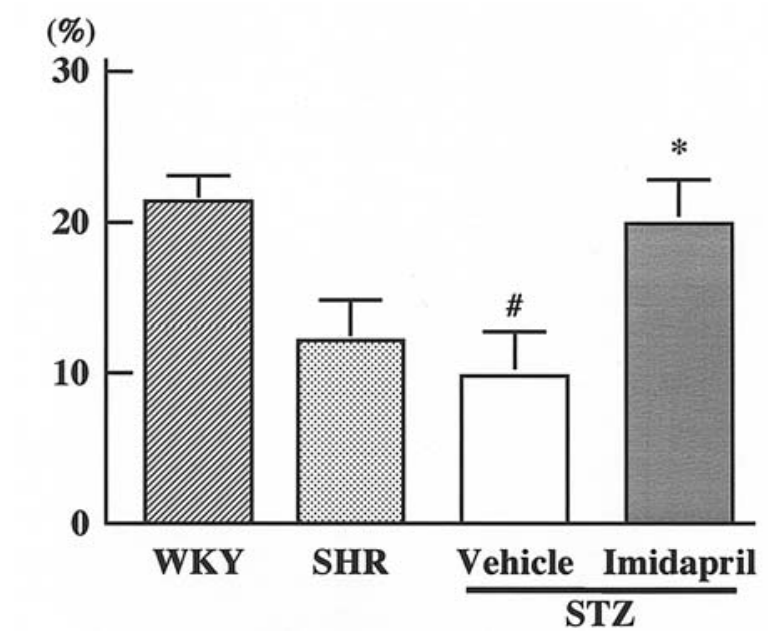

B

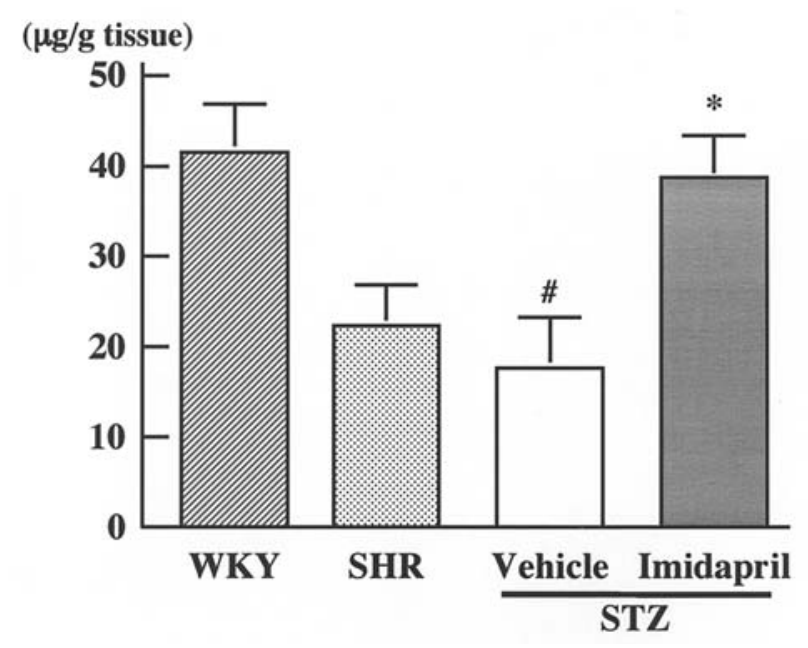

Figure 5. (A) Quantitative analysis of HGF protein as assessed by immunohistochemical staining in aorta on day 28. Values indicate the percentage of positive HGF staining in each section. (B) Vascular HGF concentration in aortas as assessed by EIA on day 28. WKY, aorta from untreated WKY; SHR, aorta from untreated SHR; Vehicle, aorta from diabetic SHR treated with vehicle; Imidapril, aorta from diabetic SHR treated with imidapril. STZ indicates the induction of diabetes by injection of streptozotocin. ${ }^{*} \mathrm{p}<0.01$ vs vehicle; ${ }^{*} \mathrm{p}<0.01$ vs WKY; $\mathrm{n}=7$ per/group. Values are mean \pm SEM.

reduction was observed in diabetic SHR treated with vehicle (WKY, 41.2 $\pm 5.1 \mu \mathrm{g} / \mathrm{g}$ tissue; SHR, 22.7 $\pm 3.8 \mu \mathrm{g} / \mathrm{g}$ tissue; Vehicle, $18.9 \pm 2.7 \mu \mathrm{g} / \mathrm{g}$ tissue; $\mathrm{p}<0.01$ vs WKY) (Fig. 5B). Similarly in the immunohistochemical study, the HGF concentration in the vessel walls in diabetic SHR treated with imidapril significantly recovered, (imidapril, 38.7 $\pm 3.9 \mu \mathrm{g} / \mathrm{g}$ tissue; vehicle, $18.4 \pm 3.2 \mu \mathrm{g} / \mathrm{g}$ tissue; $\mathrm{p}<0.01 \mathrm{vs}$ vehicle) (Fig. 5B).

\section{Discussion}

In the present study, a low dose of imidapril significantly reduced cardiac hypertrophy. With the dose we used in this study blood pressure was not decreased. This suggests that the inhibition of ACE activity in the heart may be more important than the hypotensive action. This is consistent with a previous report demonstrating that perindopril reduced 
cardiac hypertrophy after myocardial infarction (30). In this report, perindopril suppressed cardiac hypertrophy both when administered at a dose that lowered blood pressure and when administered at a dose that did not. Moreover, in SHR older than 20 weeks, we usually observe cardiac hypertrophy, whereas cardiac hypertrophy is not yet observed in younger SHR. In this study, we induced diabetes in SHR at 15 weeks of age. This induction of diabetes contributed to the development of cardiac hypertrophy at a younger age, as previously reported (31). Of course we cannot completely exclude that the decrease in the ratio of heart weight to body weight was the consequence of lower body weight in diabetic SHR. This may partially explain why we did not observe a significant reduction in the thickness of the posterior wall of the left ventricle.

In this study, a non-depressor dose of imidapril significantly reduced the increase in UAE without lowering blood pressure. Systemic hypertension is a well-known cause of progressive renal injury in both humans and experimental animals (32-34). Moreover, it was reported that captopril at a sufficient dose to lower blood pressure showed a smaller decrease in UAE compared to a dose of imidapril with a weaker hypotensive effect (15). These findings, together with our present data, suggest that the decrease in UAE in diabetic SHR was not accounted for solely by a decrease in blood pressure. Another explanation for the effects of ACE inhibitors on UAE is the amelioration of permeability properties of the glomerular basement membrane. It has been reported that ACE inhibition diminished glomerular permeability to proteins by enhancing barrier size-selectivity measured by the dextran fractional clearance in humans with diabetic glomerulopathy and rats with unilateral nephrectomy $(35,36)$. Therefore, the protection against the alteration of the glomerular basement membrane may be partially related to the mechanisms in the decrease in UAE. In this study, we showed that imidapril significantly reduced the increase in UAE, but did not affect glomerular hypertrophy. This result is consistent with previous reports investigating the effects of ACE inhibitors administered for 4-8 weeks in a streptozotocin-induced diabetic model $(34,37)$. On the other hand, several reports demonstrated that in animals treated with ACE inhibitors for 12 and 24 weeks, glomerular hypertrophy was inhibited $(38,39)$. Based on these reports we conclude that the lack of effects of imidapril on glomerular hypertrophy may be due to the short duration of treatment in this study.

As previously reported, ACE inhibitors increase the bradykinin level through inhibition of kininase and thus activate the kallikrein-kinin system (40). The increase in the bradykinin level elevates nitric oxide synthase (NOS) activity, NO production and prostacyclin production $(41,42)$. In the present study, we measured only urinary NOx excretion as a substitute for NO concentration, and found that treatment with imidapril increased urinary NOx excretion. On the other hand, in the control group, we observed a decrease in urinary NOx excretion. These results suggest that imidapril may stimulate the bradykinin-NO system. We speculate that this stimulation may contribute to the improvement of endothelial function assessed by dilator response to acetylcholine, because, as previously reported, the stimulation of the bradykinin-NO system resulted in inhibition of cell proliferation and inflammatory changes (43). Of course, the vasoprotective effect may be mediated mainly by angiotensin (Ang) II blockade. Moreover, a significant reduction in blood glucose level by treatment with imidapril was observed in diabetic SHR. This reduction is consistent with previous reports that ACE inhibitors improved insulin resistance, leading to the reduction of blood glucose levels (44-46). This reduction may also have contributed to the improvement in endothelial function.

Next, we focused on the interaction between Ang II and the vascular HGF system. HGF was initially identified as the most potent growth factor for hepatocytes and is well known as a mesenchyme-derived pleiotropic factor that regulates cell growth, cell motility, and morphogenesis of various types of cell (47). Of importance, recent studies suggest that HGF has many effects on the cells of other target organs including the endothelium. For example, in vivo gene transfer of HGF promoted the regeneration of endothelial cells subjected to balloon injury (29). In addition, our previous studies demonstrated that HGF is a potent anti-apoptotic factor in endothelial cells $(48,49)$. These observations are important, since endothelial dysfunction in diabetes and/or hypertension is often reversible, and recovery may depend on the mitogenesis, motogenesis and morphogenesis of endothelial cells. From this viewpoint, the maintenance of endothelial cells may be important for the treatment of vascular diseases. As we previously reported, a significant reduction of vascular HGF, assessed by immunohistochemical staining, was observed in diabetic SHR compared to non-diabetic WKY $(16,18)$. The suppression of vascular HGF expression might accelerate endothelial injury such as endothelial dysfunction. This phenomenon gives rise to the hypothesis that disruption of the autocrine-paracrine local HGF system in the blood vessels by Ang II may result in endothelial dysfunction, as endothelial cells secrete anti-proliferative substances $(50,51)$. The present study demonstrated that Ang II blockade by imidapril treatment resulted in improvement of endothelial dysfunction in diabetic SHR, accompanied by an increase in vascular HGF. This might have contributed to the protection against organ damage, especially endothelial dysfunction induced by diabetes and hypertension.

Overall, the present study demonstrated the protective effects of imidapril against organ damage through inhibition of the RAS in diabetic SHR, accompanied by an increase in vascular HGF and urinary NOx excretion. Moreover, these effects were observed at a low dose of imidapril that did not affect blood pressure (non-depressor dose), indicating that imidapril has effects other than blood pressure lowering. It is well known that the blood pressure of patients with other risk factors, such as hyperglycemia and hyperlipidemia, should be strictly controlled. Based on the results of this study, we conclude that inhibition of the RAS by a non-depressor dose of imidapril, an ACE inhibitor, should be considered in the treatment of patients with diabetes and hypertension.

\section{Acknowledgements}

This work was partially supported by grants from the Japan Health Sciences Foundation, a Grant-in-Aid from the 
Ministry of Public Health and Welfare, a Grant-in-Aid for the Development of Innovative Technology, a Grant-in-Aid from Japan Promotion of Science, and through Special Coordination Funds of the Ministry of Education, Culture, Sports, Science and Technology, the Japanese Government. This work was also partially supported by the KANAE foundation, Mitsui Seimei and the Osaka Kidney Foundation.

\section{References}

1. Lassila M, Davis BJ, Allen TJ, Burrell LM, Cooper ME and Cao Z: Cardiovascular hypertrophy in diabetic spontaneously hypertensive rats: Optimizing blockade of the renin angiotensin system. Clin Sci 104: 341-347, 2003.

2. Clark CM Jr and Lee DA: Prevention and treatment of the complications of diabetes mellitus. N Engl J Med 332: 1210-121, 1995.

3. Laakso M: Hyperglycemia as a risk factor for cardiovascular disease in type 2 diabetes. Prim Care 26: 829-839, 1999.

4. Cooper ME and Johnston CI: Optimizing treatment of hypertension in patients with diabetes. JAMA 283: 3177-3179, 2000.

5. Mogensen CE, Neldam S, Tikkanen I, Oren S, Viskoper R, Watts RW and Cooper ME: Randomised controlled trial of dual blockade of renin-angiotensin system in patients with hypertension, microalbuminuria and non-insulin dependent diabetes; the candesartan and lisinopril microalbuminuria (CALM) study. Br Med J 321: 1440-1444, 2000

6. The Diabetes Control and Complications Trial Research Group: The effect of intensive treatment of diabetes on the development and progression of long-term complications in insulindependent diabetes mellitus. N Engl J Med 329: 977-986, 1993.

7. The SOLVD Investigators: Effects of enarapril on survival in patients with reduced left ventricular ejection fractions and congestive heart failure. N Engl J Med 325: 293-302, 1991.

8. Pfeffer MA, Braunwald E, Moye LA, Basta L, Brown EJ Jr, Cuddy TE, Davis BR, Geltman EM, Goldman S and Flaker GC: Effects of captopril on mortality and morbidity in patients with left ventricular dysfunction after myocardial infarction: Results of the survival and ventricular enlargement trial. The SAVE investigators. N Engl J Med 327: 669-677, 1992.

9. PROGRESS Collaborative Group: Randomised trial of a perindopril-based blood-pressure-lowering regimen among 6105 individuals with previous stroke or transient ischaemic attack. Lancet 358: 1033-1041, 2001.

10. Heart Outcomes Prevention Evaluation (HOPE) Study Investigators: Effects of ramipril on cardiovascular and microvascular outcomes in people with diabetes mellitus: Results of the HOPE study and MICRO-HOPE substudy. Lancet 355: 253-259, 2000.

11. Schrier RW: Treating high-risk diabetic hypertensive patients with combined conditions. Am J Kidney Dis 36: S10-S17, 2000.

12. Cao Z, Bonnet F, Davis B, Allen T and Cooper M: Additive hypotensive and antialbumiuric effects of angiotensinconverting enzyme inhibition and angiotensin receptor antagonism in diabetic spontaneously hypertensive rats. Clin Sci 100: 591-599, 2001.

13. Matsumoto K, Morishita R, Moriguchi A, Tomita N, Yo Y, Nishii T, Matsumoto K, Nakamura T, Higaki J and Ogihara T: Prevention of renal damage by angiotensin II blockade, accompanied by increased renal hepatocyte growth factor in experimental hypertensive rats. Hypertension 34: 279-284, 1999.

14. Matsumoto K, Morishita R, Moriguchi A, Tomita N, Aoki M, Sakonjo H, Matsumoto K, Nakamura T, Higaki J and Ogihara T: Inhibition of neointima by ACE inhibitor in porcine coronary artery balloon injury model. Hypertension 37: 270-274, 2001

15. Katoh M, Ohmachi Y, Kurokawa Y, Yoneda H, Tanaka N and Narita H: Effects of imidapril and captopril on streptozotocininduced diabetic nephropathy in mice. Eur J Pharmacol 398: 381-387, 2000.

16. Matsumoto K, Morishita R, Tomita N, Moriguchi A, Yamasaki K, Aoki M, Matsumoto K, Nakamura T, Higaki J and Ogihara T: Impaired endothelial dysfunction in diabetes mellitus rats was restored by oral administration of prostaglandin I2 analogue. J Endocrinol 175: 217-223, 2002.
17. Uruno A, Sugawara A, Kanatsuka H, Arima S, Taniyama Y, Kudo M, Takeuchi K and Ito S: Hepatocyte growth factor stimulates nitric oxide production through endothelial nitric oxide synthase activation by the phosphoinositide 3-kinase/Akt pathway and possibly by mitogen-activated protein kinase kinase in vascular endothelial cells. Hypertens Res 27: 887-895, 2004.

18. Matsumoto K, Morishita R, Tomita N, Moriguchi A, Komai N, Aoki M, Matsumoto K, Nakamura T, Higaki J and Ogihara T: Improvement of endothelial dysfunction by angiotensin II blockade accompanied by induction of vascular hepatocyte growth factor system in diabetic spontaneously hypertensive rats. Heart Vessels 18: 18-25, 2003.

19. Tsuda $\mathrm{H}$, Iwase $T$, Matsumoto K, Ito M, Nishida $\mathrm{Y}$, Oyama $\mathrm{F}$, Titani K, Ushijima T, Nagao $M$ and Hirono I: Immunohistochemical localization of hepatocyte growth factor protein in pancreas islet A cells of man and rats. Jpn J Cancer Res 83: 1262-1266, 1992.

20. Nakamura T, Mizuno S, Matsumoto K, Sawa Y, Matsuda H and Nakamura T: Myocardial protection from ischemia/reperfusion injury by endogenous and exogenous HGF. J Clin Invest 106: $1511-1519,2000$

21. Yamada A, Matsumoto K, Iwanari H, Ichida T, Asakura H, Komoriya Y, Nishiyama E and Nakamura T: Rapid and sensitive enzyme-linked immunosorbent assay for measurement of HGF in rat and human tissues. Biomed Res 16: 105-114, 1995.

22. Morishita R, Gibbons GH, Ellison KE, Lee W, Zhang L, Yu H, Kaneda Y, Ogihara T and Dzau VJ: Evidence for direct local effect of angiotensin in vascular hypertrophy: in vivo gene transfer of angiotensin converting enzyme. J Clin Invest 94: 978-984, 1994.

23. Tomita N, Morishita R, Lan HY, Yamamoto K, Hashizume M, Notake M, Toyosawa K, Fujitani B, Mu W, Nikolic-Paterson DJ, Atkins RC, Kaneda Y, Higaki J and Ogihara T: In vivo administration of a nuclear transcription factor-kappaB decoy suppresses experimental crescentic glomerulonephritis. J Am Soc Nephrol 11: 1244-1252, 2000.

24. Aiello EA, Villa-Abrille MC, Escudero EM, Portiansky EL, Perez NG, Camilion de Hurado MC and Cingolani HE: Myocardial hypertrophy of normotensive Wistar-Kyoto rats. Am J Physiol 286: H1229-H1235, 2004.

25. Diamond JA and Phillips RA: Hypertensive heart disease. Hypertens Res 28: 191-202, 2005.

26. Morishita R, Nakamura S, Nakamura Y, Aoki M, Moriguchi A, Kida I, Yo Y, Matsumoto K, Nakamura T, Higaki J and Ogihara T: Potential role of endothelium-specific growth factor, hepatocyte growth factor, on endothelial damage in diabetes mellitus. Diabetes 46: 138-142, 1997.

27. Morishita R, Higaki J, Hayashi S, Yo Y, Aoki M, Nakaumura S, Moriguchi A, Matsushita H, Matsumoto K, Nakamura T and Ogihara T: Role of hepatocyte growth factor in endothelial regulation: Prevention of high D-glucose-induced endothelial cell death by prostaglandins and phosphodiesterase type 3 inhibitor. Diabetologia 40: 1053-1061, 1997.

28. Nakamura S, Morishita R, Moriguchi A, Yo Y, Nakamura Y, Hayashi S, Matsumoto K, Nakamura T, Higaki J and Ogihara T: Hepatocyte growth factor as a potential index of complication in diabetes mellitus. J Hypertens 16: 2019-2026, 1998.

29. Hayashi K, Nakamura S, Morishita R, Moriguchi A, Aoki M, Matsumoto K, Nakamura T, Kaneda Y, Sakai N and Ogihara T: In vivo transfer of human hepatocyte growth factor gene accelerates re-endothelialization and inhibits neointimal formation after balloon injury in rat model. Gene Ther 7: 1664-1671, 2000.

30. Chiba K, Moriyama S, Ishigai Y, Fukuzawa A, Irie K and Shibano T: Lack of correlation of hypotensive effects with prevention of cardiac hypertrophy by perindopril after ligation of rat coronary artery. Br J Pharmacol 112: 837-842, 1994.

31. Kohzuki M, Wu XM, Kamimoto M, Yoshida K, Nagasaka M, Kanazawa M, Yasujima M, Saito T and Sato T: Renalprotective effect of nondepressor dose of cicletanine in diabetic rats with hypertension. Am J Hypertens 13: 298-306, 2000.

32. Drury PL: Diabetes and arterial hypertension. Diabetologia 4: 1-9, 1983

33. Monensen CE and Christensen CK: Predicting diabetic nephropathy in insulin-dependent patients. N Engl J Med 311: 89-93, 1984.

34. Tikkanen T, Tikkanen I, Rockell MD, Allen TJ, Johnston CI, Cooper ME and Burrell LM: Dual inhibition of neutral endopeptidase and angiotensin-converting enzyme in rats with hypertension and diabetes mellitus. Hypertension 32: 778-785, 1998. 
35. Morelli E, Loon N, Meyer T, Peters W and Myers BD: Effects of converting-enzyme inhibition on barrier function in diabetic glomerulopathy. Diabetes 39: 76-82, 1990.

36. Cartwright ME and Jaenke RS: Effects of dietary protein and captopril on glomerular permselectivity in rat with unilateral nephrectomy. Lab Invest 59: 492-499, 1988.

37. Yotsumoto T, Naitoh T, Shikada K and Tanaka S: Effects of specific antagonists of angiotensin II receptors and captopril on diabetic nephropathy in mice. Jpn J Pharmacol 75: 59-64, 1997.

38. Sassy-Prigent C, Heudes D, Jouquey S, Auberval P, Belair MF, Michel O, Hamon G, Barriety J and Bruneval P: Morphometric detection of incipient glomerular lesions in diabetic nephropathy in rats. Protective effects of ACE inhibition. Lab Invest 73: 64-71, 1995.

39. Gilbert RE, Cox A, Wu LL, Allen TJ, Hulthen UL, Jerums G and Cooper ME: Expression of transforming growth factorbeta1 and type IV collagen in the renal tubulointerstitium in experimental diabetes: Effects of ACE inhibition. Diabetes 47: 414-422, 1999.

40. Schmaier AH: The plasma kallikrein-kinin system counterbalances the renin-angiotensin system. J Clin Invest 109: 1007-1009, 2002.

41. Linz W, Wohlfart P, Scholkens BA, Malinski T and Wiemer G: Interactions among ACE, kinins and NO. Cardiovasc Res 43: $549-561,1999$.

42. Usui M, Egashira K, Tomita H, Koyanagi M, Katoh M, Shimokawa H, Takeya M, Yoshimura T, Matsushima K and Takeya A: Important role of local angiotensin II activity mediated via type 1 receptor in the pathogenesis of cardiovascular inflammatory changes induced by chronic blockade of nitric oxide synthesis in rats. Circulation 101: 305-310, 2000.

43. Chen R, Iwai M, Wu L, Suzuki J, Min LJ, Shiuchi T, Sugaya T, Liu HW, Cui TX and Horiuchi M: Important role of nitric oxide in the effect of angiotensin-converting enzyme inhibitor imidapril on vascular injury. Hypertension 42: 542-547, 2003.
44. Rett K, Lotz N, Wicklmany M, Basta L, Brown EJ Jr, Cuddy TE, Davis BR, Geltman EM, Goldman S and Flaker GC: Improved insulin action by ACE inhibition in type II diabetes. Dtsch Med Wschr 113: 243-249, 1998.

45. Pollare T, Lithell $\mathrm{H}$ and Berne $\mathrm{C}$ : A comparison of the effects of hydrochlorothiazide and captril on glucose and lipid metabolism in patients with hypertension. N Engl J Med 321: 868-873, 1989.

46. Kodama J, Katayama S, Tanaka K, Itabashi A, Kawazu S and Ishii J: Effects of captopril on glucose metabolism. Possible role of augmented postprandial forearm blood flow. Diabetes Care 13: 1109-1111, 1990.

47. Nakamura T, Hagiya M, Nishizawa T, Seki T, Shimonishi M, Sugimura A, Tashiro K and Shimizu S: Molecular cloning and expression of human hepatocyte growth factor. Nature 342: 440-443, 1989.

48. Nakagami H, Morishita R, Yamamoto K, Taniyama Y, Aoki M, Kim S, Matsumoto K, Nakamura T, Higaki J and Ogihara T: Anti-apoptotic action of hepatocyte growth factor (HGF) through mitogen-activated protein kinase on human aortic endothelial cells. J Hypertens 18: 1411-1420, 2000.

49. Yamamoto K, Morishita R, Hayashi S, Matsushita H, Nakagami H, Moriguchi A, Matsumoto K, Nakamura T, Kaneda Y and Ogihara T: Contribution of Bcl-2 but not Bcl-xL and Bax, to anti-apoptotic actions of hepatocyte growth factor in hypoxic conditioned human endothelial cells. Hypertension 37: 1341-1348, 2001.

50. Dzau VJ: The role of mechanical and humoral factors in growth regulation of vascular smooth muscle cells and cardiac myocytes. Curr Opin Nephrol Hypertens 2: 27-32, 1993.

51. Dzau VJ and Gibbons GH: Endothelium and growth factors in vascular remodeling of hypertension. Hypertension 18 (suppl III): 115-121, 1991. 